\title{
Design socialmente responsável: ontem e hoje
}

Giordana Dos Anjos Costa;

Maria Regina Álvares Correia Dias;

Rosemary do Bom Conselho Sales

resumo:

A sociedade é construída em torno de um processo de transformações complexas, articuladas pela força da conectividade e da internet. Nessa direção, busca-se discutir sobre as contribuições do designer na dimensão social com foco no desenvolvimento sustentável. Com base em um levantamento bibliográfico e documental buscou-se compreender os conceitos e definições de desenvolvimento sustentável e design para sustentabilidade e de temas relacionados para responder à seguinte pergunta: como o design pode colaborar com projetos na dimensão social, integrando inovação e desenvolvimento sustentável? Os estudos teóricos resultaram em uma análise apoiada nos estudos de Vezzoli e produziu um importante direcionamento para possíveis ações locais na dimensão social, assim como um melhor entendimento sobre as contribuições do design para o desenvolvimento sustentável no contexto social.

\section{palavras-chave:}

Design social; Design de Sistemas; Desenvolvimento Sustentável 


\section{Introdução}

$\mathrm{Na}$ linha tríplice do desenvolvimento sustentável a dimensão social está relacionada às condições favoráveis e ideais para o ser humano como: saúde, educação, condições justas de trabalho, salários justos, moradia, segurança, igualdade de gênero, dentre outros (ELKINGTON, 1998; BRUNDTLAND, 1987). Nesta direção, e considerando que a população do planeta, nos últimos anos dobrou de tamanho, vive-se um dilema global marcado pela pobreza, falta de abrigo, desigualdades, e tantos outros problemas vividos pela humanidade. Tudo isso reflete na perda de controle sobre o que é necessário para uma vida digna e o que se deseja. Um duelo com graves consequências, como a migração de indivíduos para os grandes centros urbanos. Cynthia E. Smith, (2011), curadora de design socialmente responsável do Museu Nacional de Design Smithsonian Cooper-Hewitt, afirma que, até 2030, o número de pessoas vivendo em favelas e assentamentos irá dobrar de um bilhão para dois bilhões de pessoas. Segundo a autora pela primeira vez na história do planeta, aproximadamente sete bilhões de pessoas vivem nas grandes cidades. As possíveis causas podem estar relacionadas ao acesso limitado de serviços básicos como: saneamento e água limpa, falta de segurança em suas terras, condições de vida precária, além de almejar um bem-estar proporcionado por estas cidades. Como consequência, tem-se uma incapacidade de lidar com esse movimento e tudo o que com ele acarreta (SMITH, 2011).

Portanto, nesse cenário busca-se de profissionais como os designers, capacidades que correspondam a este contexto, que irão além do aprendizado técnico disciplinar adquirido. São capacidades desenvolvidas a partir de escolhas e oportunidades. Manzini (2017) explica que o designer atua em dois mundos, o físico e biológico - em que os seres humanos vivem e as coisas funcionam - e o mundo social, característico de um ambiente em que as coisas e ideias são construídas e desenvolvidas na base do diálogo e da produção de sentidos. O designer transita entre esses universos, mas algumas habilidades e capacidades se desenvolverão, mais ou menos, no campo das escolhas e das motivações, que o colocará mais em um universo do que em outro. Smith (2011) trata como sendo uma mudança de foco de atuação que deverá ultrapassar o percentual dedicado às verdadeiras necessidades dos indivíduos, pois "os designers profissionais tradicionalmente se concentraram nos 10 por cento da população mundial que pode pagar os seus bens e serviços" (SMITH, 2011).

Esses autores, entre outras coisas, chamam a atenção para a acumulação de conhecimento, erros e acertos, domínio, esforço e oportunidade, com o propósito de discutir criticamente a possibilidade de mudança das perspectivas futuras do design. Cardoso (2008) lembra que o campo profissional do design existe somente há cerca de cento cinquenta ou duzentos anos, e isso explica, ser esta uma área em plena formação e, por este motivo, carecer de 'discurso projetual'. Nesse sentido, orienta que, para dar maior relevância ao seu trabalho, o designer deve aprofundar-se na aprendizagem conceitual, "entender melhor e mais sistematicamente aquilo que faz, como o faz, por quê o faz, quais são as opções para fazer diferentemente" (CARDOSO, 2008). O autor acrescenta ainda que uma maior interpretação entre teoria e prática, além de um estudo e pesquisa das próprias linguagens do design, gráficas, plásticas, pictóricas ou outras, devem ser revisitados, pois é o campo da linguagem que serve como mediação. "É no campo das linguagens, na análise e no redimensionamento da sua operação, que encontramos o terreno mais fértil para aprofundar o debate conceitual que fundamenta a prática do design" (CARDOSO, 2008).

Tomando como base os preceitos de Victor Papanek (1984), ele já questionava o potencial social inexplorado e o ferramental que o designer possui e que era subutilizado em causas realmente importantes e fundamentais às necessidades do ser humano. $\mathrm{O}$ autor visionava maiores eficiências na intervenção do design na sociedade, pois reconhecia a responsabilidade dele pela forma como o mercado recebe os produtos que projeta, e atentava que o bom juízo social e moral do designer deveria entrar em jogo, de modo a saber julgar se seus projetos estão a favor ou contra o bem social. Ele responsabiliza o designer por ter desmerecido suas possibilidades criativas e não dado importância às suas responsabilidades no planejamento de produtos para se eximir do confronto com seus demandantes, sendo culpado pelos erros ecológicos cometidos.

Nessa linha de raciocínio, Papanek (1984) foi um exaustivo provocador de reflexões e seu incômodo conduziu a novas reflexões, principalmente quanto ao motivo do produto em detrimento das necessidades. A Figura 1 demonstra a atuação do designer diante das camadas de interesse e 
necessidades da sociedade, muito embora ainda permaneçam, neste quadro, como visto anteriormente por Smith (2011).

Figura 1 - Diagrama do Mundo de Papanek

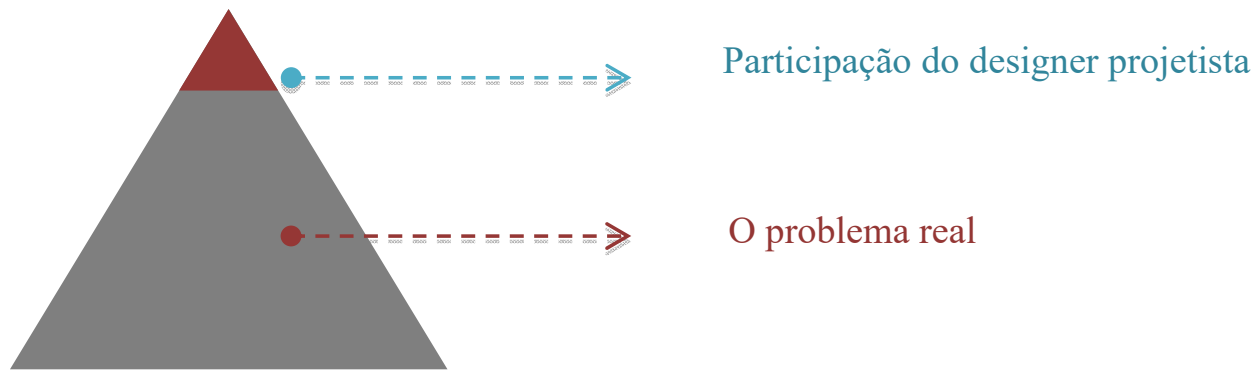

Fonte: Autor, adaptado de Papanek (1984, p. 62).

Esta observação mostra que a riqueza está concentrada nas mãos de um pequeno grupo, em que as realidades típicas dos menos favorecidos estão longe do seu alcance, e, desse modo, os projetos de design são um luxo que só prioriza esse pequeno grupo da elite em detrimento da grande população de necessitados, representados pela parte inferior do triângulo. Papanek (1984), sobre o papel do design neste contexto, reforça que iniciativas podem ser acionadas. Ele acreditava que era possível alguma ação positiva de impacto social:

[...] sempre haverá homens como Buckminster Fuller, que passa $100 \%$ do seu tempo projetando para as necessidades do homem. A maioria dos outros, não pode fazer o mesmo com dedicação exclusiva, mas acho que de modo geral, os designers poderiam dedicar $10 \%$ do seu tempo às causas e necessidades do homem. A mecânica é simples: quatro horas de cada quarenta, um dia de trabalho de cada dez, ou, o que seria ideal, dedicar a cada 10 anos, um ano sabático ao design para muitos, em vez de projetar apenas pelo dinheiro (PAPANEK, 1984, p.70).

Em linha semelhante e complementar, Gould et al. (2017) avaliam como sendo obstáculos estruturais a construção social - política, econômica e cultural - por concentrar as decisões importantes para toda a sociedade nas pessoas com poder, dificultando ou impossibilitando a superação. Complementando essa linha de argumentação, para Manzini (2015), o designer estava atendendo às necessidades da época. As novidades trazidas pela indústria demandaram, do profissional do designer, participação para gerar produtos em massa. Os processos de design eram produtos acabados, fosse ele um serviço, fosse objeto material ou artefato de comunicação. Felizmente, essa realidade mudou, como todo o resto, mas a principal diferença no contexto do design é que o foco mudou de "objetos" para "maneiras de pensar e fazer". Isso porque o mundo muda rápido e em profundidade, afetando as relações, produções e atividades cotidianas. De modo que o formato convencional de adaptação e reprodução se tornou inviável para essa nova condição do planeta (MANZINI, 2015).

$\mathrm{Na}$ verdade, as demandas mercadológicas continuarão a existir e a produção de coisas desnecessárias também, mas quando o foco se direciona em uma contribuição na forma em como a sociedade atribui valor, traduz necessidade e conceitua bem-estar, um novo cenário de possibilidades surge como viável para o design. Essa possibilidade tem base no diálogo social sobre o que fazer e como fazer, e ocorre entre aqueles interessados em resolver um problema ou abrir uma nova possibilidade de fazer e pensar. (MANZINI, 2017). De modo que, "o designer como ator social e pela natureza de sua profissão, é um mediador privilegiado, entre artefatos e pessoas, nas relações cotidianas e expectativas de bem-estar a elas atreladas" (VEZZOLI, 2010). O fato de ampliar a área de conhecimento do design para a sustentabilidade, não significa tratar de uma nova disciplina de design, mas uma nova habilidade, cuja 
capacidade de reconhecer as dinâmicas sociais promissoras e trabalhar com elas requer uma capacidade de abordar diferentes questões, que vão desde o desenvolvimento de produtos até problemas sociais, ambientais e políticos, aumentando o seu escopo e raio de ação (VEZZOLI, 2010; MANZINI, 2015).

Nesse sentido, o presente artigo traz um recorte da dissertação, Intervenção do Design como Estratégia de Desenvolvimento Social em Arranjos Produtivos Locais: uma perspectiva sobre o APL da cidade de Nova Serrana - MG. A pesquisa teve como objetivo identificar ações de design que gerem melhorias na qualidade de vida das pessoas envolvidas em projetos de arranjo produtivo local. Neste recorte, a finalidade foi discutir as contribuições do designer na dimensão social como foco no desenvolvimento sustentável ao longo do tempo.

\section{Design de sistemas para a sustentabilidade}

O conceito de design de sistemas para sustentabilidade segundo Vezzoli (2010, p.39) é o "design de sistemas de produtos e serviços ecoeficientes, socialmente coesos e equânimes, que sejam capazes de 'satisfazer' a uma demanda específica (de clientes/usuários), bem como o design da interação dos atores envolvidos no sistema de produção de valor”. A sustentabilidade precisa ser entendida também como um modo de viver, e isso significa mudar o modo como se produz e se consome. Esse feito não é possível somente com o engajamento de alguns, mas de um coletivo, um conjunto de atores e relações de sistemas (VEZZOLI, 2010). Nessa linha, Capra (1997) relaciona comunidades sustentáveis com células nucleares, argumentando que a vida na terra tem avançado por meio de arranjos cada vez mais intrincados de cooperação e de coevolução, observadas a partir da criação das primeiras células há mais de dois bilhões de anos. Portanto, a parceria é uma característica essencial, e, para o autor, a "parceria - a tendência para formar associações, para estabelecer ligações, para viver dentro de outro organismo e para cooperar - é um dos "certificados de qualidade" da vida" (CAPRA, 1997, p.221).

Sob essa perspectiva, o designer encontra-se em um território que conecta o mundo da produção e o mundo do usuário. Isso inclui o sistema de produtos, o sistema de serviços, a interação dos atores envolvidos no processo. Este é o campo de atuação do design e que possui a "função imprescindível que consiste em integrar a ciência e a tecnologia na vida cotidiana de uma sociedade, com foco na interseção entre o usuário e o produto ou informação" (BONSIEPE, 2012). Esse universo de expectativas e ações em diferentes contextos necessitam de reposicionamento, dada a importância que o design de um produto representa dentro da circularidade dos sistemas, por ter uma influência direta na forma como é gerida a cadeia de valor, tem necessitado de novas competências para atender as transformações do sistema, cujo padrão confere ainda com a criação, fabricação e comercialização de produtos. Significa fundamentalmente uma mudança na prática do design, cujas habilidades e competências variam desde um profundo conhecimento de composição material, técnicas de engenharia e processos operacionais, design de serviços até conhecimento do comportamento humano (LOS RIOS et al., 2016).

Manzini (2010) reconhece que, embora seja um processo difícil e de longo prazo, não é impossível, pois muitos já provaram ser capazes de atuar fora dos modelos econômicos convencionais. Ao mesmo tempo, a transição entre privilegiar "objetos", produtos, ferramentas e sistemas para "maneiras de pensar" e fazer, significando métodos, ferramentas, abordagens e culturas de design, é uma outra realidade. Entra em pauta o padrão de consumo e qual o acesso aos bens e serviços para poder atuar no que será feito e em como será feito, isso requer uma reflexão sobre o tipo de bem-estar que a sociedade está buscando, e que, embora as escolhas sejam individuais, os sistemas no qual o aparato é desenvolvido e produzido pertence ao coletivo, assim como o sistema de sentidos que é um produção cultural, e por isso se choca com o que produz (MANZINI, 2017).

A transição deve então ser iniciada com a sociedade, a dinâmica que a cerca promove um "padrão de relacionamento, conceitos e percepções sobre perto/longe, pertencimento/não pertencimento, possível/impossível" (VEZZOLI, 2010, p.34). Ainda segundo o autor, o trânsito de pessoas, objetos e informações que circulam áreas geográficas é resultado de uma sociedade em rede, altamente interligada e conectada, seduzida por todo o aparato de coisas desenvolvidas e pensadas para serem consumidas. Uma sociedade que mede sua condição pelo seu poder de consumo ou de produção material, é uma realidade que precisa mudar para outra capaz de viver melhor consumindo menos. A isto o autor chama de inovação sistêmica, ou seja, "somente quando uma abordagem 
considerar todos os atores e relações do sistema, é que será possível realizar seriamente a transição para a sustentabilidade" (VEZZOLI, 2010).

Desse modo, com o objetivo de avançar questões clássicas do processo de design que se concentra mais em aspectos tangíveis, alguns termos serão organizados para dimensionar abordagens que buscam ajustar o processo do design no contexto atual. A inovação, quando guiada pelo design, considera que a pesquisa e análise sobre qual é a real necessidade do usuário é o primeiro passo a ser feito, podendo ser uma pesquisa básica de design; orientada pelo design ou centrada no humano (NORMAN; VERGANTI, 2014):

- Pesquisa básica de design: tem como objetivo explorar novos significados, sem considerações específicas para processo de desenvolvimento de utilização de produtos, como, por exemplo, significados com apelo emocional, afetivo;

- Pesquisa orientada pelo design: está destinado à sua aplicação, a análise servirá para orientar o desenvolvimento de um produto ou serviço;

- Pesquisa centrada no ser humano: explora o significado que as pessoas atribuem a produtos do contexto atual e verifica suas reais necessidades e valores não correspondidos, o resultado direciona e orienta projetos equalizados, não significa produção de novos produtos necessariamente. A etnografia aplicada e a observação são os métodos primários dessa abordagem.

Rampino (2011) adiciona que, depois da teoria de qualidade total, a partir de 1990, a satisfação do cliente passou a ser perseguida como principal engrenagem na produção de novos produtos e serviços. Semelhantemente, a intencionalidade voltada às necessidades e exigências do cliente surgiu recentemente com a inovação baseada em design, considerada complementar. Sobre essa ideia voltada à satisfação do cliente, autores, como Manzini e Vezzoli, defendem inovação com resultados positivos de bem-estar, em que as necessidades em atender aos desejos sejam substituídas por uma vida com menos consumo, igualitária, justa e democrática. (VEZZOLI, 2010; MANZINI, 2015).

Nesse contexto, direcionar o foco para as reais necessidades dos indivíduos com intenção de equilibrar o que as pessoas querem, preservando o ambiente biofísico que mantém todos vivos nesse planeta, alinha-se diretamente ao conceito de desenvolvimento sustentável feito pela ONU, em 1990, que é "melhorar a qualidade de vida humana dentro dos limites da capacidade de proteger os ecossistemas". Por sua vez, isso converge com a ideia que se tem com relação ao papel do design e da sua razão de existir, citado por Vezzoli, que é melhorar a qualidade do mundo, embora seja ainda "parte dos problemas", mas pode assumir outro papel, agindo como parte da solução e tornando um agente promotor da sustentabilidade (VEZZOLI, 2010).

De modo que o direcionamento do design para sistemas e para equidade e coesão social do sistema de produtos e serviços, é, segundo Vezzoli (2010), "o design que atende a uma demanda particular de 'satisfação' (de comunidades), bem como o design de interações de atores (locais e estruturados em rede) envolvidos diretamente e indiretamente nesse sistema de satisfação. Portanto, esse equilíbrio se concretiza na busca por inovações que sejam boas para a sociedade e que ampliem a sua capacidade de ação (MANZINI, 2017), uma ação ativa, ou seja, que lhe dê condições de participar na escolha do que fazer e como. A inovação social, nesse novo cenário, parte de novas ideias de produtos, serviços e modelos "que atendem às necessidades sociais, e ao mesmo tempo, criam novas relações ou colaborações sociais" (2017, p. 25).

A Figura 2 mostra as dimensões do design para sustentabilidade, mapeadas por Vezzoli (2010), sendo elas: seleção de recursos e design de produtos com baixo impacto ambiental; design do sistema de serviços de produtos para a ecoeficiência; design para a equidade social e a coesão social. $\mathrm{O}$ autor adverte que não se trata de uma ordem cronológica de evolução e nem que exista algum limite entre elas, trata-se de um entendimento esquemático sobre as possíveis contribuições do design para a sustentabilidade. Estes precisam alcançar níveis equilibrados entre pesquisas e práticas. Nessa direção a dimensão de materiais/energia de baixo impacto está localizada em um bom nível de consolidação relacionado a pesquisas científicas, e, por outro lado, demonstra a baixa prática profissional. Entre pesquisa e prática, no campo do design, ainda se apresenta uma expressiva distância, principalmente no campo de design para equidade social, cuja consolidação e disseminação estão no nível mais baixo de desempenho e carecem ser equalizadas, equilibradas. Manzini (2017) enfatiza que algo mais 
precisa ser feito para dar apoio à inovação social, a ponte estabelecida entre tecnologia e sociedade deve ser invertida e, portanto, designers devem reconhecer casos promissores e apoiá-los a serem mais acessíveis, eficazes, duradouros e replicáveis. Nesse contexto, direcionar o foco para as reais necessidades dos indivíduos com intenção de equilibrar o que as pessoas querem, preservando o ambiente biofísico que mantém todos vivos nesse planeta, alinha-se diretamente ao conceito de desenvolvimento sustentável feito pela ONU, em 1990, que é "melhorar a qualidade de vida humana dentro dos limites da capacidade de proteger os ecossistemas". Por sua vez, isso converge com a ideia que se tem com relação ao papel do design e da sua razão de existir, citado por Vezzoli, que é melhorar a qualidade do mundo, embora seja ainda "parte dos problemas", mas pode assumir outro papel, agindo como parte da solução e tornando um agente promotor da sustentabilidade. (VEZZOLI, 2010).

Figura 2 - Diagrama dos níveis de consolidação e disseminação do design para a sustentabilidade

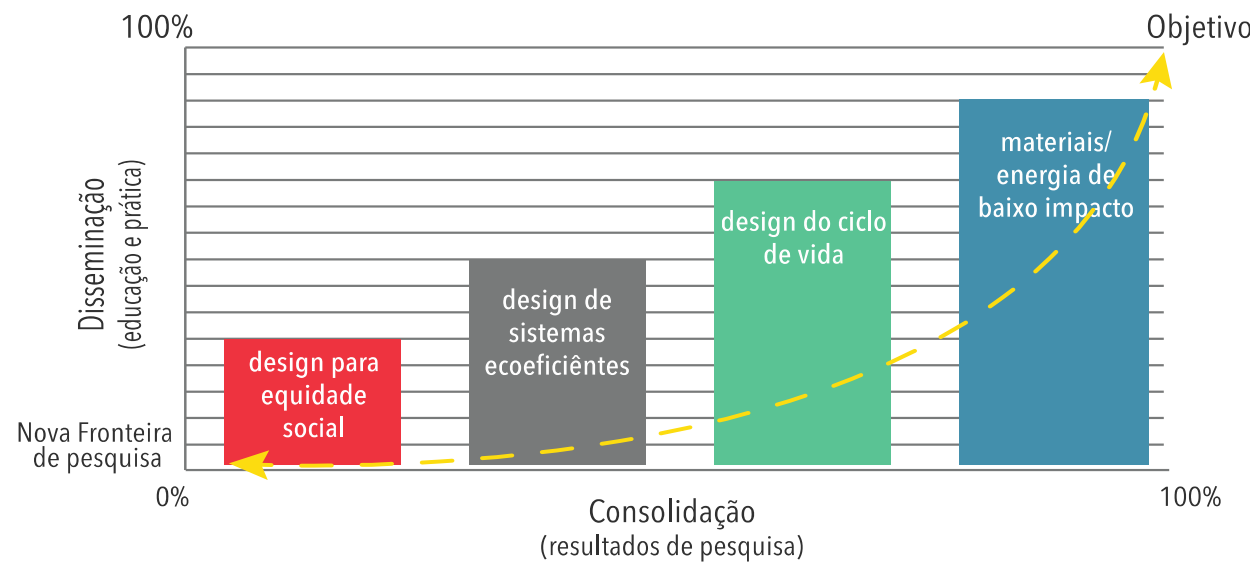

Fonte: Adaptado de Vezzoli, p. 56.

Como dito anteriormente, a baixa pesquisa e prática do design na dimensão da equidade social é uma lacuna a explorar e ser consolidada, um novo campo para o design, um momento cujo pensamento se desloca do funcional para satisfação. Os autores Manzini (2010) e Vezzoli (2014) concordam que empreendimentos e iniciativas locais, estruturados em rede, são modelos promissores, e "conduzem para a hipótese de novos e potenciais papéis para o design". De modo que o direcionamento do design para sistemas e para equidade e coesão social do sistema de produtos e serviços, é, segundo Vezzoli (2010), "o design que atende a uma demanda particular de 'satisfação' (de comunidades), bem como o design de interações de atores (locais e estruturados em rede) envolvidos diretamente e indiretamente nesse sistema de satisfação. Portanto, esse equilíbrio se concretiza na busca por inovações que sejam boas para a sociedade e que ampliem a sua capacidade de ação (MANZINI, 2017), uma ação ativa, ou seja, que lhe dê condições de participar na escolha do que fazer e como. A inovação social, nesse novo cenário, parte de novas ideias de produtos, serviços e modelos "que atendem às necessidades sociais, e ao mesmo tempo, criam novas relações ou colaborações sociais" (2017, p. 25).

\section{Design para equidade e coesão social}

Muito embora o desenvolvimento sustentável incluísse a questão social, essa dimensão claramente foi negligenciada por muito tempo em detrimento das questões ambientais e do desenvolvimento econômico. Percebe-se que se tem tratado como bens gratuitos não somente o ar, a água e o solo, mas também "a delicada teia das relações sociais, que é seriamente afetada pela expansão econômica contínua" (CAPRA, 1997, p.220). Por essa razão, antes de adentrar no campo do design, é necessário recordar onde se situa a questão de equidade e coesão social. O termo encontra-se contemplado na dimensão social de Elkington (1998) ou no Relatório Nosso Futuro Comum (BRUNDTLAND, 1987), ambos pontuam indicadores sociais, que delineiam condições favoráveis e ideais para o ser humano, 
como: igualdade de gênero, saúde, educação, condições justas de trabalho, salários justos, moradia, segurança, etc. Também a ONU (1995), na Agenda 21, estabelecida na Conferência das Nações Unidas no Rio de Janeiro, e também a União Europeia - UE (2006) com a reapreciação da estratégia para o desenvolvimento sustentável, apontam que, entre os principais objetivos-chave, está contemplada a justiça e coesão social que visa promover "uma sociedade democrática, de inclusão e coesão social, saudável, segura e justa que respeite os direitos fundamentais e a diversidade cultural que crie a igualdade de oportunidades e combata todas as formas de discriminação". Logo, situa-se em um lugar comum, em que as unidades de satisfação atendidas possibilitam maior equilíbrio nas dimensões sociais, econômica e ambiental, ou seja, no todo. É sistêmico, pois os indivíduos negligenciados em seus direitos e necessidades não correspondem à satisfação do outro, e a 'conta, além de não fechar, fica cara, sendo paga por todos', incluindo os que não possuem qualquer possibilidade de influenciar a máquina. Vezzoli (2010) reforça que a busca pela justiça e coesão social não se trata apenas de erradicar a pobreza, mas, sobretudo, da busca por possibilitar a melhoria da qualidade de vida.

Neste terreno, os autores Manzini e Vezzoli (2011) advertem que o controle do impacto provocado pelo homem no ambiente depende de três variáveis: a população, a procura por bem-estar humano e a ecoeficiência das tecnologias. Nessa perspectiva, uma sociedade sustentável é uma construção humana. Em linha semelhante, Marshall (1996) reflete também sobre o impacto que as partes de um sistema têm umas sobre as outras, quanto a sua natureza, intensidade, diversidade e intimidade, afirmando que:

[...] o desenvolvimento de um organismo, seja físico ou social, envolve uma crescente subdivisão de funções das suas diferentes partes, ao mesmo tempo em que aumenta a conexão íntima que existe entre elas. Cada uma das partes vê diminuir sua autossuficiência, e seu bem-estar passa a depender cada vez mais das outras partes, de modo que qualquer desordem em uma das partes de um organismo de desenvolvimento superior afetará também as demais partes (MARSHALL, 1996, p.294).

Manzini (2017), de maneira muito semelhante, reflete exatamente no mesmo ponto que Marshall (1996) sobre a ideia de bem-estar e o modo como o desenvolvimento de algo diminui a autossuficiência, gerando dependência de outras tantas coisas. Trata-se de substituir coisas, as habilidades e competências são substituídas por produtos e serviços a serem adquiridos facilmente, tirando o peso das atividades diárias. A necessidade de estar ou se sentir bem é reinterpretada em prol de uma economia cuja a riqueza é monetária e de um enorme custo social e ambiental (MANZINI, 2017). Essa ideia de bem-estar propagada alimenta um discurso de diminuir obrigações de toda natureza, como tempo, energia, atenção e competências. Esse modo doutrina, por meio de uma roupagem sedutora, que a solução, para algumas dores, está disponível para a venda. E com isso, os indivíduos se tornam passivos, solitários, preguiçosos e incapacitados, pois necessitam de adquirir as coisas de maneira passiva e individual para se sentir bem, que tudo precisa ser comprado e também que precisa de dinheiro. É um incansável processo cíclico que beneficia o mercado, mas não os indivíduos, como também não promove bem-estar duradouro. São reflexões que Manzini (2017) usa para discutir a respeito do que significa bem-estar neste século, bem como as diferentes maneiras de ajustar a muitas conveniências. Na direção contrária a esse bem-estar incapacitante, passivo, isolado, individualizado, é preciso possibilitar às pessoas o acesso a conhecimentos e ferramentas que as tornem ativas e capazes de resolver seus problemas.

O significado de qualidade social está condicionado ao bem-estar como aquela desejada por cada um e que deriva da complexidade das relações. Nestas relações é o lugar em que cada indivíduo encontra ou não seu bem-estar social próprio, ou seja, o que cada um sente como condição de bemestar. Neste ponto, soma-se a esse argumento o que os autores Vallance et al. (2011) denominam como sustentabilidade da manutenção; tudo aquilo que as pessoas gostariam que fosse preservado, tais como, tradições, práticas, preferências e lugares, a vida suburbana de baixa densidade, uso de carro particular, paisagens naturais preservadas, redes, oportunidades de lazer e outros são práticas que sustentam a qualidade de vida das pessoas.

Esses aspectos evidenciam que os indivíduos são seres sociais, mas também são reconhecidos como consumidores. Isso os coloca em uma situação de desejabilidades que atendam uma demanda de 
bem-estar ligada àquilo que compõe o conjunto de atributos próprios de uma sociedade saudável e funcional, como saúde, educação, segurança, lazer e também a outra demanda de bem-estar, ligada à necessidade de obter, consumir as ofertas, sejam elas produtos, sejam serviços. Advertidamente, as ofertas são uma demanda social, cujo sistema produtivo e suas modalidades cumprem em atendê-las. Essa dinâmica é o que legitima sua existência a cada decisão de adquirir e utilizar, desdobrando-se em efeitos ambientais e de escoamento final. É uma crise sobre a ideia do que seja bem-estar, trabalho e sobre o modelo de produção existente (MANZINI; VEZZOLI, 2011; MANZINI, 2017). Os autores deixam claro que não se trata de responsabilizar consumidores, pois eles são movidos por um conjunto de fatores que independem de sua vontade. Trata-se, portanto, de promover a sustentabilidade por meio da redução de recursos ambientais, da ecoeficiência empresarial ${ }^{1}$, da biocompatibilidade, reduzir a toxicidade, minimizar resíduos para otimizar a vida do sistema; reduzir consumo na distribuição e transporte, ou seja, diretrizes de ecoeficiência de um sistema (VEZZOLI, 2010). Este entendimento é importante, pois na operacionalização de uma intervenção do design para alcançar uma demanda de satisfação na dimensão social, a correta compreensão impacta diretamente no diagnóstico e na decisão de projeto. A qualidade social, proferida pelos autores Manzini e Vezzoli (2011), no cenário da sustentabilidade, está relacionada ao convívio, multipolaridade e friendliness (Quadro 1).

Quadro 1 - Referências de Qualidade social

\begin{tabular}{l|l}
\hline Convívio & $\begin{array}{l}\text { Existência de um tecido de ligações sociais e afetivas entre diferentes indivíduos. } \\
\text { E, portanto, parte de uma ou mais comunidade, que leva a ideia de sociedade, que } \\
\text { não se trata apenas da soma de indivíduos, mas do entrelaçado de redes de } \\
\text { relações operativas e afetivas, cuja solidariedade, contatos entre pessoas e a } \\
\text { democracia são qualidades sociais a serem buscadas. }\end{array}$ \\
\hline Multipolaridade & $\begin{array}{l}\text { Possibilidade de vivenciar diferentes momentos de experiências por escolha } \\
\text { própria, como poder vivenciar diferentes formas de trabalho ou diferentes } \\
\text { temporalidade, relacionada ao momento de maior força produtiva e menor força } \\
\text { produtiva; e também diferentes espacialidades, nas quais se pode vivenciar o } \\
\text { mundo pelas relações virtuais as relações de vizinhança. }\end{array}$ \\
\hline Friendliness & $\begin{array}{l}\text { Possibilidade de vivenciar suas próprias capacidades livremente e da melhor } \\
\text { maneira, oportunizando todos a se sentirem capazes, considerados. Do ponto de } \\
\text { vista dos projetistas, devem favorecer e valorizar a relação com os usuários ao } \\
\text { pensar em produtos e serviços. Possibilitar ferramentas ou produtos amigáveis, } \\
\text { ou seja, respeitoso em face de diferentes capacidades e amigáveis para o planeta } \\
\text { também. }\end{array}$ \\
\hline
\end{tabular}

Fonte: Adaptado de Manzini e Vezzoli (2011, p.59-61).

Desse modo, relativo à abordagem do design para a equidade e a coesão social, segundo Vezzoli (2010, p.155), ela pode ser definida como um "sistema de produto e serviço que conjuntamente, atendem a uma demanda particular de 'satisfação' (de comunidades), bem como o design de interações de atores (locais e estruturados em rede) envolvidos diretamente e indiretamente nesse sistema de "satisfação". E acrescenta que deve formatar um sistema de produção e consumo economicamente competitivo e socialmente justo e coeso. Em síntese está caracterizada por: basear-se na interação dos atores envolvidos; pautar-se pela demanda por satisfação; orientar-se para a sustentabilidade, ou seja, por um processo de design ambiental e socioeticamente orientado.

Nesse contexto a intervenção do designer deve estar relacionada ao processo dirigido às necessidades e não somente a fatores de produção, cabendo-lhe a responsabilidade de contemplar um conjunto de características como: intenção de criar condições de trabalho que permitam ao homem o

\footnotetext{
${ }^{1}$ A ecoeficiência operativa de uma empresa é o grau de eficiência econômica e ecológica de que ela é capaz ao produzir um determinado produto-serviço em um determinado contexto. Melhores práticas obtidos através do re-design do sistema necessário para esta ação (MANZINI; VEZZOLI 2011, p.82-83).
} 
pleno desenvolvimento de sua capacidade criativa; fabricação de produtos úteis, duráveis, fáceis de reparar, 'emancipatórios'; uso responsável dos recursos necessários para obter esses objetivos; ergonomia; estética; comunicação; símbolos, ciclo de vida do produto, viabilidade de produção em termos de custo e viabilidade de recurso para o consumidor final (BONSIEPE, 2012). Esses aspectos exigem das empresas, como atores sociais que são dentro do sistema de produção e consumo, uma postura direcionada à sustentabilidade. Esta deve estar alinhada à sua condição competitiva, ou seja, em qualquer escolha favorável, a sustentabilidade só pode acontecer se não prejudicar sua competitividade. Logo, a abordagem usada com as empresas, nesse sentido, necessariamente deve convergir favoravelmente com sua condição normativa, econômica, sociocultural e técnica e ainda precisa estar traduzida em uma vantagem relativa ao aumento de sua competitividade em um prazo de curto, médio ou de longo prazo (MANZINI; VEZZOLI, 2011).

Avalia-se, nesse sentido, a complexa e ampla dimensão que toma o assunto por não ser de fácil operacionalização, uma vez que depende de várias escalas, como políticas de apoio econômico e ambiental para dar conta da política de curto prazo. E por ser sistêmico, impacta na demanda de bemestar e na urgência em reduzir o consumo de recursos ambientais. Desta maneira, compreende-se um vasto campo de oportunidades do design se tornar agente a favor da sustentabilidade, visto que sua posição se encontra entre responder às demandas de bem-estar das empresas e dos usuários com responsabilidade ambiental. Nesse sentido, o designer pode trabalhar usando melhor as tecnologias ou no posicionamento estratégico, caracterizado no diferencial que um produto-serviço pode oferecer e ser reconhecido pelo cliente como sendo melhor que o do concorrente (MANZINI; VEZZOLI, 2011).

A contribuição do design também está na sua habilidade clínica de identificar um sistema inadequado, com possibilidades de melhorar fluxo produtivo, operacional, relacional, e de oferta, promovendo e ou facilitando novos empreendimentos sustentáveis locais e estruturados em rede, devido ao seu caráter instrumental, ou seja, de intervenção ativa sobre a produção voltada a satisfazer usuários de todos os níveis no sistema. Sobre a promoção ou facilitação de empreendimentos sustentáveis, Elkington (2012) levanta algumas questões como: seria possível medir o impacto da empresa sobre os stakeholders e ainda avaliar o progresso nas operações direcionadas a sustentabilidade? Qual o papel do executivo para sustentar o capital humano e o capital social? Essas e outras questões podem balizar a tomada de decisão pelo design. $O$ autor chama a atenção a mecanismos de controle, como contabilidade e auditoria social (ELKINGTON, 2012, p.128 - 129).

Contabilidade social: tem como objetivo avaliar o impacto de uma organização sobre as pessoas internas e externas. As questões consideradas nesta análise são: relações com a comunidade, segurança do produto, iniciativa de treinamento e educação, suporte financeiro, donativos em forma de dinheiro e tempo e geração de empregos para grupos menos favorecido. Auditoria social: é entendida sob o ponto de vista de impacto não financeiro das empresas. Seu objetivo é fazer com que a empresa avalie seu desempenho em relação às exigências e expectativas da sociedade. Em linha semelhante, um conjunto de requisitos o Quadro 2 foi elaborado para orientar o design rumo a soluções eficientes, direcionadas à equidade e coesão social, em que o designer deve ser capaz de "promover e fomentar relações justas e equânimes (fora da empresa), em parcerias e nas comunidades onde existe a oferta de produto e serviço" (VEZZOLI, 2010, p. 164-166). Os requisitos e diretrizes terão maior relevância, dependendo do projeto e da unidade de satisfação que se deseja alcançar, ou seja, é necessário identificar em qual sistema está relacionado o esforço do design para "formatar um sistema de produção e consumo economicamente competitivo e socialmente justo e coeso".

Quadro 2 - Diretrizes para o design rumo a soluções de equidade e coesão social 


\begin{tabular}{|c|c|}
\hline \multirow{5}{*}{ 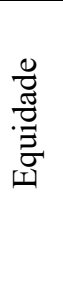 } & Promover e fomentar parceria justas e equânimes. \\
\hline & $\begin{array}{l}\text { 2. Promover e fomentar relações justas e equânimes entre fornecedores, terceirizados e } \\
\text { subfornecedores. }\end{array}$ \\
\hline & 3. Promover e fomentar relações justas e equânimes com clientes e com usuários finais. \\
\hline & $\begin{array}{l}\text { 4. Promover e fomentar relações justas e equânimes, influenciando a comunidade na qual a oferta } \\
\text { acontece. }\end{array}$ \\
\hline & 5. $\quad$ Promover e fomentar equidade e justiça com agências e instituições locais. \\
\hline \multirow{8}{*}{ 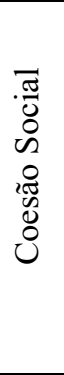 } & Promover sistemas que habilitem a integração entre vizinhos. \\
\hline & Promover sistemas de compartilhamento e manutenção de bens comuns entre vizinhos. \\
\hline & $\begin{array}{l}\text { 8. Promover sistemas habilitantes para moradores participarem no desenvolvimento de bens comuns } \\
\text { (codesign). }\end{array}$ \\
\hline & 9. $\quad$ Promover sistemas de comoradia. \\
\hline & 10. Promover sistemas co-working. \\
\hline & 11. Promover sistemas que habilitem a integração entre gerações. \\
\hline & 12. Promover sistemas que habilitem a integração entre gêneros. \\
\hline & 13. Promover sistemas que habilitem a integração entre diferentes culturas. \\
\hline
\end{tabular}

\section{Considerações finais}

Diante do exposto, torna-se necessário que os designers coloquem sua atividade a serviço da sociedade. A intencionalidade na ação é a diferença que revela o centro de poder e as pessoas submetidas a ele, o desequilíbrio é antidemocrático. É indispensável uma reformulação para o encontro de uma sociedade mais equilibrada, justa, branda e participatória, mas, muito provavelmente, seja preciso que eventos aconteçam fora do estreito profissional e com a participação de cada indivíduo como cidadão, de modo a fomentar a consciência crítica e emancipatória mediante seu processo metodológico em identificar necessidades, direcionando à produção de projetos que contribuam para estimular o grupo a alcançar independência de escolha por meio da reflexão e interpretação, visto que o humanismo implica a redução da dominação e, portanto, não se desdobra em novas necessidades e dependências (BONSIEPE, 2012).

A sociedade, para ser sustentável, precisa inovar no que faz e no modo como faz, e o design, quando opera nessa direção, funciona ativando, sustentando e orientando processos de mudança, disponibilizando suas ferramentas, habilidades e capacidades. Nesse rumo, o designer deve ter a capacidade dialógica; capacidade de administrar o equilíbrio entre a necessidade de lançar ideias e reunir conceitos de outras pessoas; de planejar o ponto de retirada no projeto e, portanto, seria também a capacidade de estimular a autonomia dos atores envolvidos; capacidade de convergir visões comuns e organizá-las em diferentes iniciativas; mapear e planejar o encontro dos serviços necessários; publicar e estabelecer uma comunicação durante todo o processo; capacidade de identificar casos promissores existentes e ajudá-los a ser mais acessíveis, eficazes, duradouros e replicáveis, entre outros.

Todas essas capacidades devem ser operacionalizadas pelo diálogo e codesign, ou seja, um design para a inovação social (MANZINI, 2017). O autor direciona a alguns estágios de ações com a seguinte questão: como especialistas em design podem contribuir para fazer desse contexto um ecossistema no qual comportamentos ativos, colaborativos e sustentáveis sejam mais prováveis? Nesse sentido, o profissional deve colocar em primeiro plano o indivíduo, sua qualidade de vida, necessidades que comprometem seu bem-estar, potencialidades e conhecimentos. Projetos de design socialmente responsáveis devem concentrar no processo e no entorno, na construção de um conhecimento que nasce a partir do encontro entre conhecimento acadêmico e não acadêmico, design difuso e design especializado. 
Socially responsible design: yesterday and today

Abstract: Society is built around a process of complex transformations, articulated by the strength of connectivity and the internet. In this sense, we seek to discuss the designer's contributions to the social dimension with a focus on sustainable development. Based on a bibliographic and documentary survey, we sought to understand the concepts and definitions of sustainable development and design for sustainability and related themes to answer the following question: how can design collaborate with projects in the social dimension, integrating innovation and sustainable development? Theoretical studies resulted in an analysis supported by Vezzoli's studies and produced an important direction for possible local actions in the social dimension, as well as a better understanding of the contributions of design to sustainable development in the social context.

Keywords: Social design; Systems Design; Sustainable development 


\section{Referências bibliográficas}

BONSIEPE, Gui. Design como prática de projeto. São Paulo: Blucher, 2012.

BRUNDTLAND, G. H. Nosso futuro comum. Comissão Mundial sobre o Meio Ambiente e Desenvolvimento. 2. ed. Fundação Getúlio Vargas: Rio de Janeiro, 1991. (Português).

CAPRA, Fritjof. A teia da vida: uma nova compreensão científica dos sistemas vivos. São Paulo: Editora Cultrix. 1997.

CARDOSO, Rafael. Design: objetivos e perspectivas. In: LIMA, Guilherme Cunha (Org.). Design: objetivos e perspectivas. Rio de Janeiro: PPDESDI-Uerj, 2005.

ELKINGTON, John. Sustentabilidade: Canibais com garfo e faca. São Paulo: M. Books, 2012.

GOULD, Rachael et al. Using social sustainability principles to analyse activities of the extraction lifecycle phase: Learnings from designing support for concept selection. Journal of Cleaner Production, v. 140, n.1, p. 267-276, 2017.

MANZINI, Ezio. Design para inovação social e sustentabilidade: comunidades criativas, organizações colaborativas e redes projetuais. Rio de Janeiro: E-Papers, 2008.

MANZINI, Ezio. Small, local, open and connected: design for Social innovation and Sustainability. The journal of Design strategies - Change Design. Parsons The New School for Design, v. 4, n. 1, p. 811, Spring 2010.

MANZINI, Ezio. Design, When everybody designs: an introduction to Design for Social Innovation. Translated by Rachel Coad. Cambridge: MIT Press, 2015.

MANZINI, Ezio. Design, quando todos fazem design: Uma introdução ao design para a inovação social. São Leopoldo: Ed. Unisinos, 2017.

MANZINI, Ezio. Making things happen - Social innovation and design. Politecnico di Milano. s.d.

MARSHALL, Alfred. Princípios de economia. São Paulo: Abril Cultural, 1996.

NORMAN, D.; VERGANTI, R. Incremental and radical innovation: design research versus technology and meaning change. Design Issues, v. 30, n. 1, Winter 2014.

ORGANIZAÇÃO DAS NAÇÕES UNIDAS. Conferência das Nações Unidas sobre o Meio Ambiente e Desenvolvimento: de acordo com a Resolução no 44/228 da Assembleia Geral da ONU, de 22-1289, estabelece uma abordagem equilibrada e integrada das questões relativas a meio ambiente e desenvolvimento: a Agenda 21 - Brasília: Câmara dos Deputados, Coordenação de Publicações, 1995.

PAPANEK, Victor. Design for the real world: human ecology and social change. 2. ed. Londres: Thames \& Hudson, 1984.

RAMPINO, L. The innovation pyramid: a categorization of the innovation phenomenon in the productdesign field. International Journal of Design, v.5, n.1, p. 3-16, 2011.

SMITH, Cynthia E. Design with the Other 90\%: Cities. Places Journal, Oct.2011.

VALLANCE, Suzanne et al. What is social sustainability? A clarification of concepts. Geoforum, n. 42, p. 342-348, 2011.

VERGANTI, Roberto. Design Driven Innovation: Mudando a regra da competição: A inovação radical do significado de produtos. São Paulo: Canal Certo, 2012.

VEZZOLI, Carlo. Design de Sistemas para a Sustentabilidade: Teoria, métodos e ferramentas para o design sustentável de "sistemas de satisfação". Salvador: EDUFBA, 2010.

VEZZOLI, Carlo et al. Product-Service System Design for Sustainability. Greenleaf Publishing: 2014. 